\title{
A prospective post-partum evaluation of renal function in preeclampsia
}

\author{
Akarsh Cheroth Asokan, Seena Kakkanat Babu* \\ Department of Obstetrics and Gynecology, Government Medical College, Hospital, Thrissur, Kerala, India
}

Received: 03 August 2020

Accepted: 17 August 2020

\section{*Correspondence:}

Dr. Seena Kakkanat Babu,

E-mail: seenakakkanatbabu@gmail.com

Copyright: $\odot$ the author(s), publisher and licensee Medip Academy. This is an open-access article distributed under the terms of the Creative Commons Attribution Non-Commercial License, which permits unrestricted non-commercial use, distribution, and reproduction in any medium, provided the original work is properly cited.

\section{ABSTRACT}

Background: Hypertensive disorder comprises one of the leading causes of maternal and perinatal morbidity and mortality across the globe. Because women with preeclampsia are at risk of cardiovascular disease and end-stage renal disease, proper follow-up after delivery for resolution of proteinuria and hypertension is required and investigations should be conducted to find out and adequately treat any underlying cardiovascular or renal disease.

Methods: This was a prospective study and included as participants pregnant women with preeclampsia who met the inclusion and exclusion criteria and who subsequently delivered at Government Medical College Hospital, Thrissur, Kerala, India. For each eligible participant, clinical and laboratory data were collected from third trimester of antenatal period, and six weeks and three months after delivery.

Results: In this study, it is found that $26.2 \%$ and $4.23 \%$ patients had persistence of systolic blood pressure at 6 weeks and 3 months postpartum where as $19.4 \%$ and $3.38 \%$ had persistence of diastolic blood pressure at 6 weeks and 3 months post-partum. Serum creatinine was persistently high in $14.4 \%$ and $6.77 \%$ after 6 weeks and 3 months postpartum respectively. Proteinuria resolved completely in non-severe preeclampsia by 6 weeks postpartum itself. In severe preeclampsia group, $65 \%$ and $25 \%$ of patients had persisting proteinuria after 6 weeks and 3 months postpartum.

Conclusions: Hypertension that persists more than 6 weeks postpartum usually represents a pathology not directly associated with pregnancy such as essential hypertension or underlying endocrine, neurological, or renal disease. Proteinuria that persists beyond 6-12 weeks postpartum may also warrant further investigation, particularly in early onset preeclampsia, the group of women most likely to have underlying renal disease.

Keywords: Hypertension, Postpartum renal status, Preeclampsia, Proteinuria, Urine protein creatinine ratio

\section{INTRODUCTION}

Preeclampsia is a disorder which affects $1-10 \%$ of pregnant women worldwide. It is a pregnancy-specific disease with multisystem involvement. It is thus only possible to reduce preeclampsia related mortality through early detection, careful monitoring, and treatment of the symptoms and timely delivery. ${ }^{1}$ WHO estimates the incidence of preeclampsia to be seven times higher in developing countries. ${ }^{2}$

It is a multisystem disease and several organs are affected at different stages of disease. Haematological changes associated most commonly is thrombocytopenia, haemolysis and intravascular coagulation. Commonly affected systems are renal system (manifested by reduced GFR, proteinuria, hyperuricemia and occasionally oliguria), liver (manifested by elevated transaminases with or without epigastric and right upper quadrant pain), and the brain (manifested by headaches, transient visual disturbances due to occipital lobe ischaemia and rarely convulsions, i.e. eclampsia). All this leads to increased maternal morbidity. Major maternal complications include HELLP syndrome, DIC, acute renal failure, placental abruption, pulmonary oedema, cardiac arrest and cerebral haemorrhage. The most common cause of 
maternal death is intracranial haemorrhage, which is usually secondary to severe systolic BP and acute renal failure due to abruptio placenta. The risk of death is higher in women developing antepartum eclampsia. ${ }^{3}$

Preeclampsia accounts for a third of acute kidney injury occurring in advanced pregnancy, with high risks of progression to end-stage renal disease (ESRD). ${ }^{4}$ The renal involvement in preeclampsia resulting in glomerular endotheliosis which is characterized by proteinuria and renal failure. After delivery, hypertension, proteinuria and renal failure are expected to resolve progressively. ${ }^{5}$ However, hypertension and proteinuria can persist for years after delivery, necessitating further investigations for possible underlying renal disease. Meanwhile, renal failure highly correlates with blood pressure levels and renal function usually assumes the normal range within postpartum. ${ }^{6}$ Follow-up of women after delivery has been less-than-optimal in most of the studies. Therefore, knowledge of the long-term outcomes of preeclampsia among Indian women remains limited. However, microalbuminuria without impairment of renal function has been found several years after pregnancies complicated by preeclampsia suggesting persistent endothelial damage at least in some cases. ${ }^{7-9}$

This study was conducted to monitor the time-trend in blood pressure levels, renal function and proteinuria from antenatal period, six weeks postpartum and three months postpartum in women with preeclampsia delivering in Government Medical College, Thrissur, department of obstetrics and gynecology. The presence of proteinuria after pregnancy complicated by preeclampsia have value in predicting future development of chronic hypertension, residual renal abnormality or underlying vascular disease. ${ }^{10}$

\section{METHODS}

This was a prospective study. This study was conducted for 1 year from $1^{\text {st }}$ November 2018 to $31^{\text {st }}$ October 2019. Patients included were those diagnosed to have preeclampsia attending in department of obstetrics and gynecology, Thrissur Medical College, Kerala and subsequently delivering at our institution. The study was carried out in department of obstetrics and gynecology, Government Medical College, Thrissur. This hospital is a tertiary care referral center for Thrissur, Palakkad and Malappuram districts.

\section{Inclusion criteria}

Blood pressure more than $140 / 90 \mathrm{mmHg}$ and proteinuria $>300 \mathrm{mg} / 24$ hour after 20 weeks of pregnancy was included in this study.

\section{Exclusion criteria}

Patients with preexisting kidney or liver disease, patients diagnosed to have multiple pregnancy, patients with any preexisting malignancies, patients with preexisting autoimmune or connective tissue disorders, patients who were lost to follow-up, not willing to give consent were excluded from the study.

\section{Sample size}

Fisher's formula for sample size determination is used for sample sizing.

$\mathrm{n}=\mathrm{Z}^{2} \mathrm{pq} / \mathrm{d}^{2}$

where $\mathrm{P}=48.1$

$\mathrm{Q}=100-\mathrm{P}=51.9$

$\mathrm{Z}=1.96$ Absolute precision is taken as $5 \%$.

$$
\frac{1.96 \times 1.96 \times 48.1 \times 51.9}{(20 / 100 \times 48.1)^{2}}
$$

Sample size calculated was 103.5 .

In authors institution total number of deliveries in this 1 year was 2713 of which there were 206 cases of preeclampsia. After fulfilling the inclusion exclusion criteria 118 patients were taken as study sample. In this observational study 118 women with preeclampsia who were evaluated and managed at Government Medical college Thrissur were recruited. An informed consent form was obtained from the subjects. The study protocol was approved by institutional ethics committee. For each eligible participant, authors collected clinical and laboratory data from third trimester of antenatal period (one day before delivery and 6 weeks and three months after delivery). Clinical data include age, BMI, systolic and diastolic blood pressure, pregnancy characteristics (gravidity, parity, gestational age, mode of delivery, gestational age at preeclampsia detected, gestational age of delivery, socioeconomic status, educational status of patient, birth weight and outcome, sex of the baby. Laboratory data included blood urea and serum creatinine, urine PC ratio. Secondary variables were derived from primary variables using validated formulas. Estimated glomerular filtration rate (eGFR) was based on the Cockroft-Gault formula. ${ }^{11}$

\section{Statistical analysis}

The collected data was coded and entered in MS excel and analysed using appropriate statistical procedure (SPSS software). The statistical significance was ascertained by $\mathrm{p}$ value $<0.05$.

\section{RESULTS}

A total of 118 patients were followed up in this 1-year long study. The following variables were studied

A total $94.9 \%$ of patients were taking antihypertensives. 
Maximum number of patients were from the age group of 21-30 years, amounts to $67.8 \%$ and mean age was 26 . Mean BMI in non-severe preeclampsia was 24.56 , severe preeclampsia group was 25.67 which was significant. Mean gestational age at detection of preeclampsia and delivery were 32.6 and 36.1 respectively (Table 1 ).

Table 1: Comparison of basic characteristics between two groups.

\begin{tabular}{|c|c|c|c|c|c|}
\hline \multirow{2}{*}{ Characteristic } & \multirow{2}{*}{ Groups } & \multirow{2}{*}{ Mean } & \multirow{2}{*}{ SD } & \multicolumn{2}{|c|}{ Non severity versus severity } \\
\hline & & & & t-value & P-value \\
\hline \multirow{3}{*}{ Age (years) } & Non-severe & 26.9 & 5.1 & \multirow{2}{*}{1.09} & \multirow{2}{*}{$0.28, \mathrm{NS}$} \\
\hline & Severe & 25.8 & 4.9 & & \\
\hline & Overall & 26.5 & 5.1 & - & \\
\hline \multirow{3}{*}{ Weight (kg) } & Non-severe & 61.84 & 9.06 & \multirow{2}{*}{-1.02} & \multirow{2}{*}{$0.31, \mathrm{NS}$} \\
\hline & Severe & 63.68 & 9.14 & & \\
\hline & Overall & 62.42 & 9.08 & - & \\
\hline \multirow{3}{*}{ BMI } & Non-severe & 24.56 & 1.10 & \multirow{2}{*}{-4.32} & \multirow{2}{*}{$<0.001, \mathrm{HS}$} \\
\hline & Severe & 25.67 & 1.65 & & \\
\hline & Overall & 24.91 & 1.39 & - & \\
\hline \multirow{3}{*}{ GA (weeks) when preeclampsia detected } & Non-severe & 32.7 & 2.8 & \multirow{2}{*}{0.55} & \multirow{2}{*}{$0.58, \mathrm{NS}$} \\
\hline & Severe & 32.4 & 3.0 & & \\
\hline & Overall & 32.6 & 2.8 & - & \\
\hline \multirow{3}{*}{ GA (weeks) at delivery } & Non-severe & 37.0 & 0.0 & \multirow{2}{*}{33.59} & \multirow{2}{*}{$<0.001, \mathrm{HS}$} \\
\hline & Severe & 34.2 & 0.8 & & \\
\hline & Overall & 36.1 & 1.4 & - & \\
\hline
\end{tabular}

Table 2: Severity and blood urea levels.

\begin{tabular}{|llllll|}
\hline \multirow{2}{*}{ Period } & Groups & & & \multicolumn{2}{c|}{ Non severity versus severity } \\
\cline { 2 - 6 } & Overall (\%) & Non-severe (\%) & Severe (\%) & t-value & P-value \\
\hline Antenatal & $30.1(8.3)$ & $28.9(7.6)$ & $32.8(9.2)$ & -2.39 & 0.02, S \\
\hline 6 weeks postpartum & $25.5(2.5)$ & $25.2(2.2)$ & $26.1(2.9)$ & -1.69 & 0.09, NS \\
\hline 3 months postpartum & $24.6(2.3)$ & $24.8(2.3)$ & $24.2(2.2)$ & 1.36 & 0.18, NS \\
\hline
\end{tabular}

Table 3: Severity and serum creatinine.

\begin{tabular}{|llllll|}
\hline \multirow{2}{*}{ Period } & Groups & & & \multicolumn{3}{c|}{ Non severity versus severity } \\
& Overall (\%) & Non-severe (\%) & Severe (\%) & t-value & P-value \\
\hline Antenatal & $1.21(0.57)$ & $1.03(0.33)$ & $1.60(0.75)$ & -5.74 & $<0.001$, HS \\
\hline 6 weeks postpartum & $0.82(0.30)$ & $0.71(0.06)$ & $1.07(0.44)$ & -7.34 & $<0.001, \mathrm{HS}$ \\
\hline 3 months postpartum & $0.75(0.18)$ & $0.70(0.04)$ & $0.85(0.29)$ & -4.49 & $<0.001, \mathrm{HS}$ \\
\hline
\end{tabular}

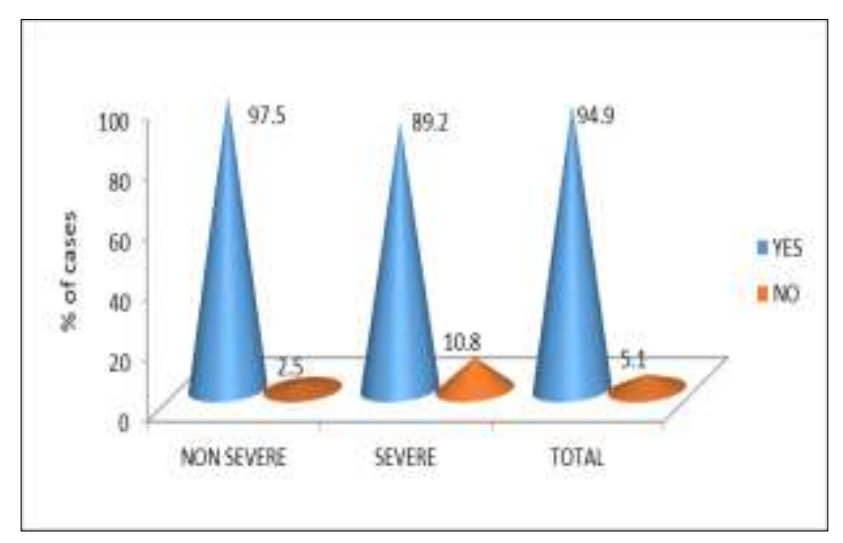

Figure 1: Relation between adherence to drugs and preeclampsia.

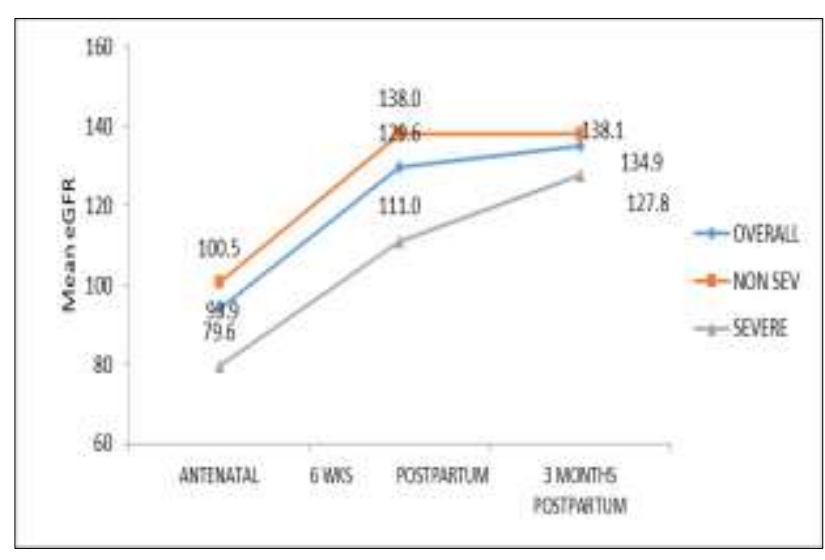

Figure 2: Severity and GFR levels. 


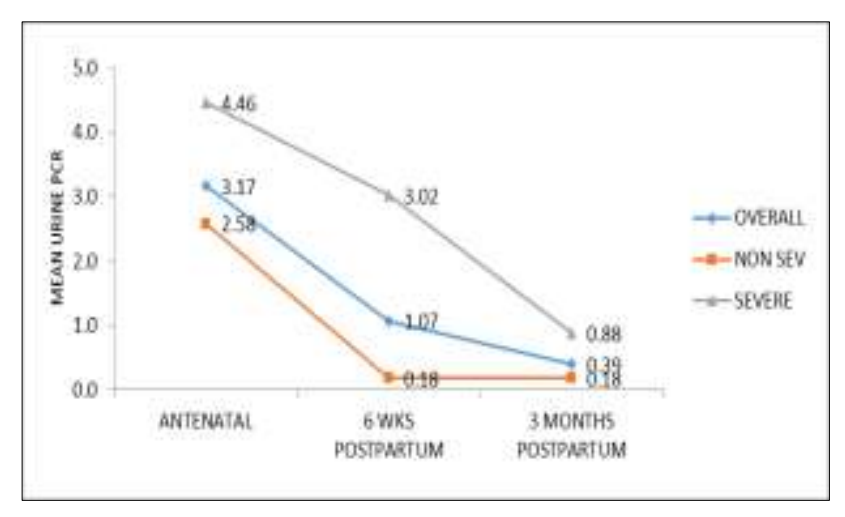

Figure 3: Severity and urine PCR levels.

Mean birth weight was $2.17 \mathrm{~kg}$ and on comparing birth weight between non severe preeclampsia and severe preeclampsia group, birth weight was 2.23 and 2.05 respectively which was statistically significant. Majority of patients delivered vaginally $(55.9 \%$ term deliveries and $27.1 \%$ preterm deliveries), $16.9 \%$ ended in LSCS.

Blood urea levels were normal after post-partum in both groups. By postpartum, creatinine values became normal in both the groups. By postpartum, GFR values became normal in both the groups.

In severe preeclampsia group, proteinuria was persisting even after 3 months whereas proteinuria resolved completely in non-severe pre-eclampsia group.

Systolic BP came to normal value by 6 weeks postpartum for non-severe preeclampsia group, where as in severe preeclampsia group it took 3 months.

Table 4: Severity and BP-systolic.

\begin{tabular}{|llllll|}
\hline \multirow{2}{*}{ Period } & Groups & & & \multicolumn{2}{c|}{ Non severity versus severity } \\
& Overall (\%) & Non-severe (\%) & Severe (\%) & t-value & P-value \\
\hline Antenatal & $155.0(21.2)$ & $141.7(3.8)$ & $184.3(12.3)$ & -28.44 & $<0.001$, HS \\
\hline 6 weeks postpartum & $140.1(20.4)$ & $132.4(12.9)$ & $156.9(23.8)$ & -7.27 & $<0.001$, HS \\
\hline 3 months postpartum & $125.5(10.9)$ & $122.2(6.5)$ & $132.8(14.7)$ & -5.44 & $<0.001$, HS \\
\hline
\end{tabular}

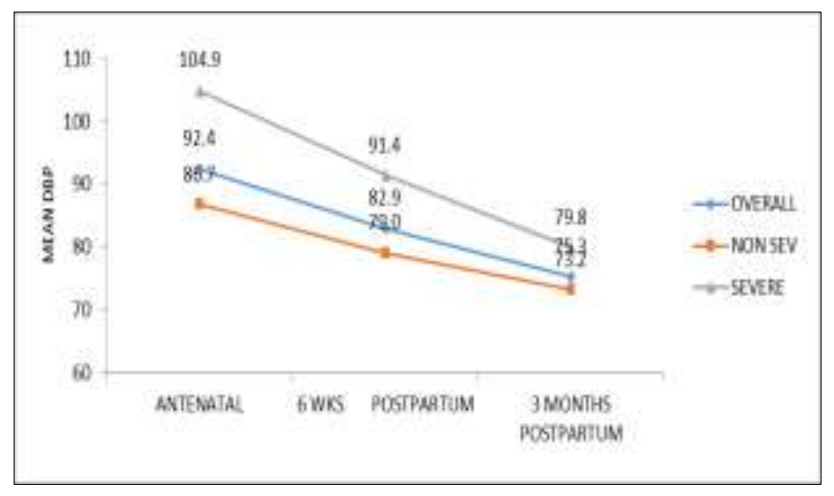

Figure 4: Severity and BP-diastolic.

Diastolic BP came to normal value by 6 weeks postpartum for non-severe preeclampsia group, where as in severe preeclampsia group it took 3 months.

\section{DISCUSSION}

Majority of the patients were in the age group 21-30 and constituted $67.8 \%$. Mean age was 26.9 and 25.8 for nonsevere and severe preeclampsia respectively. This is similar to study of Saini et al which was 26.3 and 27.2. ${ }^{12}$

Mean BMI of the study was $24.5 \mathrm{~kg} / \mathrm{m}^{2}$ and $25.6 \mathrm{~kg} / \mathrm{m}^{2}$ respectively for non-severe and severe preeclampsia. BMI in severe preeclampsia group is slightly less than the study of Saini et al which was $27.6 \mathrm{~kg} / \mathrm{m}^{2}$. Mean gestational age at which preeclampsia diagnosis made were 32.7 weeks and 32.4 weeks respectively for nonsevere and severe preeclampsia.

In this study, preeclampsia was more common in primigravida's accounts to $57.6 \%$. The present finding of increased incidence of pre-eclampsia in primigravida's was in agreement with the study conducted by Kumar P et al and Sajith et al study, where $61 \%$ and $53.8 \%$ of preeclampsia cases were of primigravida's. ${ }^{13}$

Patients those who were on antihypertensives was $94.9 \%$, which may be because of better health accessibility in Kerala.

Mean birth weight found in this study was $2.23 \mathrm{~kg}$ and $2.05 \mathrm{~kg}$ respectively in two groups. Most of the patients had a term vaginal delivery $(55.9 \%), 27.1 \%$ delivered preterm and $16.9 \%$ underwent LSCS.

Base line mean systolic BP were 132 and $156 \mathrm{mmHg}$ after 6 weeks postpartum and 122.2 and $132 \mathrm{mmHg}$ after 3 months postpartum respectively in non-severe and severe preeclampsia. Baseline mean diastolic BP were 79 and $91.4 \mathrm{mmHg}$ after 6 weeks and 73.2 and $79.8 \mathrm{mmHg}$ after 3 months in both the groups. The difference of systolic and diastolic BP between two groups were statistically significant ( $\mathrm{p}$ value 0.001 ). In this study, it is found that $26.2 \%$ and $4.23 \%$ patients had persistence of systolic BP at 6 weeks and 3 months postpartum where as $19.4 \%$ and $3.38 \%$ had persistence of diastolic BP at 6 weeks and 3 months postpartum. The overall resolution of hypertension was $96.6 \%$ at the end of 3 months 
postpartum, which was comparable to the study of Saini et al. Serum creatinine were persisted high in $14.4 \%$ and $6.77 \%$ after 6 weeks and 3 months postpartum respectively. Mean serum creatinine was 0.7 and 1.07 in non-severe preeclampsia and severe preeclampsia after 6 weeks postpartum, 0.7 and 0.8 after 3 months postpartum in the two groups.

Proteinuria resolved completely in non-severe preeclampsia patients by 6 weeks postpartum itself. In severe preeclampsia group, $65 \%$ and $25 \%$ of patients had persisting proteinuria after 6 weeks and 3 months postpartum. This result is different from other studies. In a study by Kaleta et al, proteinuria was persisting $58 \%$ of preeclampsia patients at 1 year postpartum, in an another study by Durkberk et al proteinuria persisted in $21 \%$ and $14 \%$ patients after 6 weeks and 3 months postpartum. ${ }^{14}$ In a study by Kaze et al $48.1 \%, 31.5 \%$ and $1.8 \%$ patients had persisting proteinuria at 6 weeks, 3 months and 6 months post-delivery respectively. ${ }^{15}$

In this study, $14.4 \%$ and $6.77 \%$ of patients had abnormal GFR values after 6 weeks and 3 months postpartum. These results where different from other studies where in $40 \%$ of patients had abnormal GFR after 1 year in a study by Kaleta et al. ${ }^{16}$

In another study by Kaze et al $24.1 \%$ of patients had renal filure and renal function became normal after 6 weeks of delivery. ${ }^{15}$

\section{CONCLUSION}

For most of the women, hypertension will resolve within the 1st week after delivery. Hypertension that persists more than 6 weeks postpartum usually represents a pathology not directly associated with pregnancy such as essential hypertension or underlying endocrine, neurological, or renal disease. These women should have their hypertension confirmed with ambulatory monitoring and referred for investigation for a secondary cause for their hypertension. Proteinuria that persists beyond 6-12 weeks postpartum may also warrant further investigation, particularly in early onset preeclampsia, the group of women most likely to have underlying renal disease.

Funding: No funding sources

Conflict of interest: None declared

Ethical approval: The study was approved by the Institutional Ethics Committee

\section{REFERENCES}

1. Portelli M, Baron B. Clinical presentation of preeclampsia and the diagnostic value of proteins and their methylation products as biomarkers in pregnant women with preeclampsia and their newborns. J Preg. 2018;2632637.

2. World Health Organization. The World health report: 2005: make every mother and child count. World Health Organization; 2005.

3. Sibai BM. Diagnosis, differential diagnosis and management of eclampsia. Am J Obstet Gynecol. 2005;105:402-10.

4. Côté AM, Brown MA, Lam E, von Dadelszen P, Firoz $\mathrm{T}$, Liston RM, et al. Diagnostic accuracy of urinary spot protein: creatinine ratio for proteinuria in hypertensive pregnant women: systematic review. BMJ. 2008;336:1003-6.

5. Aggarwal N, Suri V, Soni S Chopra, Kohli HS. A prospective comparison of random urine proteincreatinine ratio vs 24-hour urine protein in women with preeclampsia. Medscape J Med. 2008;10:98.

6. Piccoli GB, Attini R, Parisi S, Vigotti FN, Daidola G, Deagostini MC, et al. Excessive urinary tract dilatation and proteinuria in pregnancy: A common and overlooked association. BMC Nephrol. 2013;14:52.

7. Chua S, Redman C. Prognosis for pre-eclampsia complicated by $5 \mathrm{~g}$ or more of proteinuria in 24 hours. Europ J Obstet Gynecol Reprod Biol. 1992;43(1):9-12.

8. Bar J, Kaplan B, Wittenberg C. Microalbuminuria after pregnancy complicated by pre-eclampsia. Nephrol Dialysis Transplant. 1999;14(5):1129-32.

9. Nisell H, Lintu H, Lunell NO, Mollerstrom G, Pettersson E. Blood pressure and renal function seven years after pregnancy complicated by hypertension. $\mathrm{Br} \mathbf{J}$ Obstet Gynaecol. 1995;102(11):876-81.

10. Ihle BU, Long P, Oats J. Early onset preeclampsia : recognition of underlying renal disease. $\mathrm{Br}$ Med $\mathrm{J}$. 1987;294:79-81.

11. Ferreira JP, Girerd N, Pellicori P, Duarte K, Girerd S, Pfeffer MA, et al. Renal function estimation and Cockcroft-Gault formulas. BMC Med. 2015;14(1):181.

12. Saini V, Gupta M, Kumar DS, Singh H, Gupta SK. Preeclampsia: postpartum resolution of hypertension, proteinuria and serum $\mathrm{N}$-terminal B-type natriuretic peptide. Indian J Med Biochem. 2019;23(2):278-86.

13. Sajith M, Nimbargi V, Modi A, Sumariya R, Pawar A. Incidence of pregnancy induced hypertension and prescription pattern of antihypertensive drugs in pregnancy. Int J Pharma Sci Res. 2014;23:4.

14. Berks D, Steegers EA, Molas M, Visser W. Resolution of hypertension and proteinuria after preeclampsia. Obstet Gynecol. 2009;114(6):1307- 14.

15. Kaze FF, Njukeng FA, Kengne AP, Ashuntantang G, Mbu R, Halle MP, et al. Post-partum trend in blood pressure levels, renal function and proteinuria in women with severe preeclampsia and eclampsia in Sub-Saharan Africa: A 6-months cohort study. BMC Preg Childbirth. 2014;14(1):134.

16. Kaleta T, Stock A, Panayotopoulos D, Vonend O, Niederacher D, Neumann M, et al. Predictors of impaired postpartum renal function in women after preeclampsia: results of a prospective single center study. Dis Markers. 2016;7861919.

Cite this article as: Asokan AC, Babu SK. A prospective post-partum evaluation of renal function in preeclampsia. Int J Reprod Contracept Obstet Gynecol 2020;9:3617-21. 